\title{
MÉDICA DA (E NA) FLORESTA: A TRAJETÓRIA DE UMA PARTEIRA, PAJÉ E BENZEDEIRA TEMBÉ TENETHERAR
}

\author{
Ana Lídia Nauar Pantoja ${ }^{1}$
}

\begin{abstract}
RESUMO
A proposta deste artigo é fazer uma reflexão sobre a importância dos saberes tradicionais e práticas de curas tradicionais entre os povos indígenas Tembé Tenethehar, Nordeste do estado do Pará, por meio das narrativas biográficas de uma parteira, pajé e benzedeira da Aldeia Ytuaçu. A pesquisa de caráter exploratória com utilização do método biográfico e história oral, teve os dados submetidos à análise qualitativa, apontando para a importância que as mulheres assumem na comunidade e em particular a parteira Francisca, cuja trajetória revela a tradição de uma medicina popular que nem sempre é valorizada no contexto das políticas de atenção à saúde indígena que vêm sendo implementadas pelo Estado no local, apontando, com isso, para os riscos de desenraizamentos de valores culturais ancestrais essenciais à preservação das suas tradições e identidades.
\end{abstract}

Palavras-chave: Parteiras. Saúde. Medicina popular. Saberes ancestrais.

\section{DOCTOR (AND/IN THE) FOREST: THE PATH OF A MIDWIFE, PAJÉ AND TEMBÉ TENETHEHAR FAITH HEALER}

\begin{abstract}
The purpose of this article is to reflect on the importance of traditional knowledge and traditional healing practices among the Tembé Tenethehar indigenous peoples, in the northeast of the state of Pará, through the biographical narratives of a midwife, shaman and healer from Aldeia Ytuaçu. The exploratory research using the biographical method and oral history, had the data submitted to qualitative analysis, pointing to the importance that women assume in the community and in particular the midwife Francisca, whose trajectory reveals, the tradition of popular medicine that it is not always valued in the context of indigenous health care policies that have been implemented by the State and at the local level, thereby pointing to the risks of uprooting ancestral cultural values essential to the preservation of their traditions and identities.
\end{abstract}

Keywords: Midwives. Health. Popular medicine. Ancestral knowledge.

Data de submissão: 23.04 .2021

Data de aprovação: 23.05.2021

\section{INTRODUÇÃO}

As doenças e as preocupações em torno da saúde sempre estiveram presentes em todas as sociedades humanas, e, assim, pode-se considerá-las universais. Cada sociedade ou grupo social desenvolveu, ao longo do tempo, suas formas particulares de organização coletiva, atualizadas em práticas e ideias pautadas em lógicas culturais próprias e específicas na busca de soluções para as diversas situações apresentadas. No campo da saúde, do mesmo modo, todas as sociedades humanas desenvolveram ideias e materiais em busca de conhecimentos e técnicas que fossem capazes de dar respostas aos episódios de doenças vivenciados de forma individual ou coletiva. Com esse objetivo, toda sociedade e cada uma em particular, também

${ }^{1}$ Doutora em Antropologia Social. Professora Adjunta IV de Antropologia Social na Universidade do Estado do Pará, Centro de Ciências Sociais e Educação. Coordenadora do Programa de Pós-Graduação em Educação Escolar Indígena - PPGEEI (UEPA/UFPA/UFOPA/UNIFESSPA). E-mail: ananauar@uepa.br. 
desenvolveu conhecimentos, práticas e instituições que aqui compreende-se como "sistemas de atenção à saúde", tal como propõem Langdon e Wiik (2010). Nesse sentido, parto do pressuposto de que, sendo a cultura um fenômeno universal, ela oferece uma visão de mundo às pessoas, que orienta as suas práticas e saberes na vida cotidiana de um modo geral, nas quais também se encontram inseridas as questões relativas à saúde e à doença. Ou seja, não é possível separar os conhecimentos, técnicas e práticas em saúde, dos outros aspectos da cultura de uma sociedade ou indivíduo.

A Amazônia brasileira é palco de uma diversidade cultural enorme que se atualiza, entre outros aspectos, no rico universo simbólico das diversas práticas de cura tradicionais e saberes em torno da gestação e do nascimento das crianças. Nas sociedades indígenas, o nascimento em domicílio é parte da cultura e da tradição secular que se mantém, apesar das interferências do conhecimento, da prática médico-hospitalar e a imposição do saber médico científico. No contexto de comunidades tradicionais como as indígenas, os partos domiciliares se inserem e fazem parte de uma rede de significados simbólicos que expressam saberes que são pautados nas crenças culturais e no conhecimento da natureza.

Neste artigo, realizo uma breve reflexão sobre a importância dessas práticas para a manutenção e fortalecimento das identidades dos povos indígenas, a partir da trajetória e história de vida de Francisca dos Santos Tembé, parteira tradicional da aldeia Tembé Ytuaçu, na parte alta do rio Guamá, localizada no município de Santa Luzia, Nordeste do estado do Pará. Trata-se uma mulher de importância reconhecida na aldeia por deter saberes ligados às atividades realizadas como parteira e, também, como pajé e "rezadeira" (benzedeira) no local. Dentre as tantas mulheres do mesmo modo importantes na aldeia, a escolha recaiu em Francisca pela sua trajetória de vida, pelo reconhecimento coletivo de sua atuação como detentora de saberes de cura e como parteira, e por ser uma grande referência para seu povo, Tembé Tenetherar. Trata-se, portanto, de uma mulher sábia, muito valorizada na aldeia pela sua atuação como rezadeira bem como pelas práticas de cura realizadas como pajé e ainda pelos inúmeros partos feitos, de gerações diversas de mulheres na comunidade onde mora atualmente.

Tomei conhecimento da sua história através das alunas e alunos indígenas, em janeiro de $2015^{2}$. Na ocasião das aulas, como parte das atividades ministradas no contexto da disciplina História Indígena na Amazônia, solicitei aos grupos de alunos, que entrevistassem pessoas que a sua comunidade julgasse importantes e fundamentais no local por sua atuação em prol do coletivo e sua contribuição à história e cultura do grupo, e, uma das escolhidas foi a parteira Francisca. Ouvi várias histórias de mulheres trazidas pelos grupos de alunas e alunos Tembé Tenetehar e a da parteira me chamou atenção em particular, pela sua importância na continuidade e fortalecimento do grupo por meio de suas práticas culturais tradicionais, já que ela, sendo filha de parteira, "pegou" crianças que formam algumas gerações atuais da comunidade e durante muitos anos é a pessoa responsável pelos rituais de cura e benzeções, sobretudo, de crianças da aldeia.

Neste ponto, importa ressaltar a centralidade que as mulheres indígenas, como as do povo Tembé Tenetehar, assumem no contexto de suas lutas históricas e culturais. É exemplar nessa direção a grandeza da liderança política e cultural da aldeia Tekohaw, Verônica Tembé. A partir de fins do século passado, como posto por Ivânia Neves (2018), Verônica liderou as lutas em defesa do território Tembé e, portanto, assumiu um papel fundamental no processo de reconhecimento e demarcação da Terra Indígena (TI) Alto Guamá. Ponte e Teisserenc (2013, p. 1), em estudo sobre o aprendizado e a transmissão de conhecimento na aldeia

\footnotetext{
${ }^{2}$ Precisamente, pela turma de História, do curso Intercultural Indígena, da Universidade do Estado do Pará (UEPA), quando uma disciplina fora por mim ministrada. Agradeço, portanto, a turma, pela oportunidade de conhecimento e aprendizado sobre as experiências e importância das mulheres na organização e fortalecimento da identidade cultural do povo Tembé Tenetherar.
} 
Tembé Tenetherar, apontam como os saberes e práticas tradicionais encontram-se relacionados às ações coletivas no território que envolve muitos conflitos e, cujo contexto, as mulheres assumiram historicamente papel importante na luta e defesa do território e, consequentemente, na manutenção da identidade étnica do grupo. As autoras ressaltam que, sobretudo na década de 1950, época em que os homens das aldeias estiveram envolvidos nas frentes de atração criadas pelo Serviço de Proteção ao Índio (SPI), momento em que eles se ausentaram das aldeias, as mulheres tiveram que ficar à frente, assumindo responsabilidades na defesa de seu povo.

Nesse contexto de luta pelo território, elas imprimiram outras dinâmicas que favoreceram o seu papel como líderes, como foi o caso de Verônica Tembé que assumiu o controle político de todo o grupo. Além de aproximar os Tembé que se encontravam dispersos ao longo do Rio Gurupi e com isso criou uma nova aldeia - a aldeia Tekohaw - ela também atualizou novas formas de valorização da cultura do grupo por meio de ações de incentivo ao fortalecimento de sua língua nativa, de seus rituais ancestrais e práticas tradicionais, dentre estas as de cura. Nesse sentido, as autoras mostram como as práticas relativas ao cuidado do corpo e da saúde por meio de rituais de iniciação e outros, assumiram importante lugar enquanto "estratégia de revalorização de costumes e saberes, associada às lutas por direitos, em especial, o direito ao próprio território" (PONTE; TEISSERENC, 2013, p. 2). E em um desses importantes rituais descritos pelas autoras (o ritual da Festa da Moça), resta evidente a importância dos saberes (e poderes) das mulheres enquanto "donas da festa", pois são elas que, "por meio de um canto, clamam aos espíritos da floresta por proteção às 'meninas moças' e aos rapazes" (PONTE; TEISSERENC, 2013, p. 7). Esse mesmo tipo de conexão com os espíritos "encantados" da natureza, veio à tona nas narrativas de Francisca quando se referiu ao dom que deles recebeu para fazer os partos e os rituais de cura como pajé e benzedeira.

Assinalo que este texto tem por base a pesquisa exploratória que teve início na sala de aula e posteriormente se estendeu para a comunidade, momentos em que pude conversar e entrevistar Francisca ${ }^{3}$. Nesse sentido, tomo por base a metodologia de narrativa biográfica que privilegia a história oral e a centralidade do indivíduo nas narrativas, neste caso a da parteira Francisca. Convém deixar claro que trabalhos dessa natureza guardam uma certa complexidade, pois que a ideia de história de vida pressupõe uma "unidade do eu" que na verdade é inexistente, portanto, ilusória, como nos ensina Bourdieu (2006), em seu clássico estudo "A ilusão biográfica". Este autor propõe a ideia de "fragmentação do eu" em oposição ao que ele denominou de "unidade do eu", ou seja, a ilusão de uma linearidade, como uma série de acontecimentos que seguem uma ordem cronológica. Nesse sentido, a narrativa biográfica revela o caráter dinâmico da trajetória do indivíduo, ou seja, o movimento em múltiplas direções que é peculiar a todo processo histórico, e aqui se incluem as experiências vividas pelo indivíduo ao longo do tempo, e, portanto, envolve (ou pode envolver) outros também, pois não se faz uma história sozinha(o).

E no que diz respeito particularmente à importância da biografia de mulheres, esta reside na valorização de sujeitos que por muito tempo tiveram suas práticas invisibilizadas por uma história que se dizia oficial, posto que, como sabe-se, as mulheres e suas experiências históricas, sempre foram consideradas de menor importância. O método biográfico nesse sentido se coloca como o campo perfeito à verificação de lacunas utilizadas pelos excluídos da história, entre estes sujeitos, as mulheres. E, se considerar-se o componente étnico-racial neste caso as mulheres indígenas - esta invisibilidade, silenciamento e exclusão da história ganha dimensões muito maiores.

\footnotetext{
${ }^{3}$ Aproveito para registrar aqui a minha enorme gratidão para com a Dona Francisca Tembé, por sua gentileza e generosidade em me receber em sua casa na aldeia e confiar a mim suas experiências em torno das práticas de pajelança e como parteira e benzedeira tradicional de seu povo.
} 
Particularmente, no contexto da Amazônia, é de fundamental importância dar visibilidade às experiências de mulheres que por muito tempo tiveram suas histórias negadas por uma lógica instrumental e positivista que tem relegado-as a uma posição de inferioridade e subalternidade. Face a essa realidade, há, pelo menos, três ou quatro décadas, pesquisadoras e pesquisadores locais, sobretudo da área de Ciências Humanas e Sociais, tem procurado suprir essa lacuna e cada vez mais investido em pesquisas nas quais as mulheres assumem o lugar de sujeitas principais. Nessa esteira, ressalto a importância das publicações do Grupo de Pesquisa Eneida de Morais - GEPEM/UFPA - que inclusive atualmente possui uma Revista Eletrônica intitulada "Revista Gênero na Amazônia", que tem contribuído substancialmente na divulgação semestral de pesquisas de excelência, cujos temas têm sido as mulheres e suas experiências na região. Também nesse sentido, destaco a Enciclopédia "Mulheres PanAmazônidas", organizada por Simonian (2011), que traz uma contribuição inédita no sentido de construir uma contralógica, oferecendo - por meio das várias biografias apresentadas no mesmo volume - uma proposta de compreensão das mulheres biografadas como sujeitas de uma história da Amazônia (ou de parte dela), contada por elas mesmas, trazendo experiências culturais relevantes e diversas tornando possível ao público mais amplo, conhecê-las em suas particularidades e complexidades.

Assim, e com o intuito de valorizar a voz de uma mulher indígena da Amazônia, apresento e analiso a seguir a trajetória de vida de Francisca dos Santos Tembé. O desafio assumido aqui é o de tentar compreender, a partir das suas experiências, as (re) significações da arte e do ofício de partejar e as alterações que essa prática sofreu (e vem sofrendo) nas últimas décadas, na Aldeia Ytuaçu. Ressalto, nesse sentido, que esta reflexão se insere (também) no contexto das relações e significados das práticas realizada pelas parteiras tradicionais na Amazônia, as quais, ainda que em número mais reduzido atualmente, permanecem em muitas comunidades tradicionais assumindo papel importante na sua reprodução, como é também o caso de inúmeras comunidades quilombolas no estado do Pará. No contexto específico da Aldeia Ytuaçu, essa prática vem, aos poucos, com a introdução do subsistema de saúde médico, deixando de ser frequente, o que é visto com certa preocupação sobretudo por Francisca e pelas mulheres de sua geração.

Os povos Tembé Tenetehar se encontram em territórios pertencentes aos estados do Pará e Maranhão, separados pelo Rio Gurupi. De acordo com Wagley e Galvão (1961), eles falam a mesma língua - o tupi guarani - possuem a mesma tradição cultural e consideram pertencer a um único povo que se autodenomina Tenetehar. A antropóloga Vanderlúcia Ponte (2014, p. 29), em sua tese de doutorado desenvolveu uma rica análise sobre a relação entre território e saúde desse povo, na qual destaca que eles foram diferenciados na percepção de viajantes naturalistas que os identificaram como dois subgrupos: o grupo que se fixou na região do Maranhão foi denominado Guajajara, e o que ficou na região do Pará, foi denominado Tembé. De acordo com a autora, embora tenham sido considerados como pertencentes a um único grupo, eles guardam diferenças culturais marcantes um em relação ao outro.

\section{ORIGEM E TRAJETÓRIA DE FRANCISCA E SUA FAMÍLIA}

Francisca dos Santos Soares Tembé nasceu - pelas mãos de uma parteira, a Senhora Antonina dos Santos Farias, que era sua avó materna -, na aldeia Tembé Ytuaçu, na parte alta do rio Guamá, em 25 de outubro de 1959 e, atualmente, está com 61 anos. Filha de Luiza Agostinha Farias (que também era parteira) e Félix Sarmento dos Santos, que era "funcionário braçal da FUNAI", ou, como ele era conhecido pelo órgão, "amansador de índio", ela é a terceira filha do casal que teve um total de seis filhos, todos nascidos na mesma aldeia. 
Francisca casou-se aos 15 anos com Pedro Soares Tembé, que é raizeiro ${ }^{4}$ e caçador na mesma aldeia. Junto com ele constituiu sua família, teve seu primeiro filho com 15 anos de idade, logo após se casar. No mesmo local e ao longo de mais de 40 anos, viu sua família crescer a partir do casamento de seus filhos, a formação de suas famílias e o nascimento de seus netos.

Ao lado de seu marido e com a expansão da sua família, ela criou a aldeia Ytuwaçu no ano de 1984, onde vive atualmente. Esta aldeia é constituída principalmente pelos seus descendentes, dentre estes, filhos, netos e, agora, bisnetos. Atualmente ela tem sete filhos, 25 netos e quatro bisnetos. Portanto, Francisca descende diretamente de uma família de mulheres parteiras e pajés de povo Tembé Tenetehar. Tanto sua mãe quanto sua avó materna partejavam e praticavam também a pajelança nas aldeias onde moravam.

Nesse ambiente de mulheres sábias, Francisca cresceu vendo sua mãe e sua avó exercitarem essas práticas ancestrais. Pelo relato dela e de outras pessoas da aldeia, ficou patente que o conhecimento em torno da prática de partejar foi sendo mantido e repassado às mulheres de sua família, por várias gerações, tratando-se, portanto, de um saber ancestral intergeracional. A sua mãe Luíza foi a parteira que "pegou" os seus sete filhos e por sua vez, ela e seus irmãos foram "pegos" pela avó materna que se chamava Antonina dos Santos Farias. São mulheres sábias pertencentes a várias gerações de uma mesma família de parteiras que se sucederam ao longo do tempo no mesmo local. Tal como também acontece em outros povos indígenas da Amazônia, entre os Tembé Tenetehar - a exemplo dos povos indígenas da região do Baixo Amazonas, pesquisados por Vaz Filho (2016) - as mulheres são as principais guardiãs dos saberes e práticas de cura tradicionais ligadas ao mundo cosmológico desses povos.

\section{A MEDICINA POPULAR E A PAJELANÇA}

Falar das práticas das mulheres parteiras, pajés e curandeiras no contexto amazônico é situá-las, portanto, no âmbito de seus universos cosmológicos e como parte de um sistema simbólico que possui lógicas culturais específicas. Nesse sentido, em uma conversa que tive com Francisca em um fim de tarde no quintal de sua casa, ela ressaltou que, apesar de ter convivido desde a infância com mulheres de sua família que atualizavam cotidianamente práticas e saberes em torno da pajelança e do ofício de partejar, ela atribui seu conhecimento em torno dessas práticas, a um dom, uma missão, pois compreende ter sido escolhida pelos seres encantados da natureza (das matas ou dos rios) - conhecidos também por Caruanas ${ }^{5}$ para seguir a carreira de pajé e parteira. Sempre se referindo a tais seres com muito respeito, ela ressaltou que foi deles que recebeu as orientações e conhecimentos em torno das mesmas práticas. Ela conta que, embora nunca os tenha visto, desde criança sentia a presença dos Caruanas que se comunicavam com ela e chegavam a "perturbá-la", dada sua resistência em atender aos seus chamados.

Assim, após muito relutar em atender aos chamados dos Caruanas, finalmente começou a atuar como pajé já na sua fase adulta - aos 27 anos de idade - após muita "perturbação" dos encantados acabou cedendo e conta que passou a exercer o dom especialmente a partir de um episódio inusitado. Em seu relato, há referência de um certo dia, quando sentiu um mal-estar no corpo seguido de desmaio, tendo permanecido desacordada

${ }^{4}$ Raizeiro é o nome dado à pessoa (geralmente um homem) na aldeia que conhece a floresta e sabe onde estão as raízes e vai apanhá-las quando as pessoas delas necessitam para tratamento de saúde.

${ }^{5}$ Caruanas é o termo também conhecido, evocado e referido no contexto da pajelança cabocla amazônica para designar os seres encantados da natureza. De acordo com Dona Zeneida Lima (1992, p. 165-166), "quem cura são os Caruanas através do pajé. [...] e eles são seres encantados, donos dos mistérios do mundo (p. 135)". Essa autora, indígena e pajé da ilha de Marajó, no Pará, ressalta ainda sobre isso que: "Se não fosse pelos ataques, a doença inexplicável e o rápido desenvolvimento do meu poder de cura, exercido desde cedo, eu não seria diferente de tantas crianças em minha idade.” 
durante 20 dias. Nesse tempo, apenas dormiu e ficou sem comer e beber nada. Ela acredita que os Caruanas a protegeram durante esse tempo, pois, do contrário, não teria sobrevivido tantos dias sem comer e beber água. Ela tomou esse evento como um sinal de que deveria seguir os seus ensinamentos e, desse modo, quando voltou a si, resolveu atender aos chamados deles e começou a fazer os trabalhos de cura na aldeia.

Ao estudar a medicina popular na Amazônia rural e se detendo particularmente na "pajelança cabocla", Maués (1994) destaca que esta é uma prática secular na região, sendo constituída por um conjunto de práticas de cura xamanística. Segundo este autor, tais rituais guardam suas origens nas crenças e costumes dos indígenas Tupinambás antigos, sincretizados após o contato com os brancos e negros a partir da segunda metade do século XVIII. Dentre as crenças que sustentam e dão significado às mesmas práticas, está a crença nos "encantados" - os Caruanas - que são seres invisíveis que se apresentam durante os rituais de cura incorporados no pajé ou xamã.

Apesar da existência de outras medicinas nas áreas rurais amazônicas, o autor ressalta que ainda é o pajé (eu diria, também, a pajé), que desempenha o papel de médico (ou médica) popular mais importante nas comunidades. Esse (ou essa) especialista ${ }^{6}$ (mulher ou homem) é, em geral, alguém que conhece profundamente os remédios da fauna e da flora e quase sempre exerce também as funções de benzedor ou benzedeira e de parteira ${ }^{7}$. Segundo Maués (1994), quando a parteira também é pajé, passa a ser muito solicitada por se tratar de uma "parteira de dom", ou seja, aquela que trabalha com a assistência dos "encantados" Caruanas, das florestas ou dos rios.

De fato, tais aspectos, como se pode perceber, parecem mesmo ocupar parte importante da história de vida de Francisca. O ofício de partejar ela iniciou aos 33 anos de idade e, de acordo com seu relato, teria acontecido no contexto de uma emergência, em que uma mulher grávida e em trabalho de parto, necessitou de alguém que "pegasse" o seu bebê. Ou seja, na ausência de sua mãe que era a parteira conhecida e oficial da aldeia, ela teve que fazer o parto tendo sido bem-sucedida na missão cuja orientação ela atribui aos Caruanas.

Ressalta ainda Francisca que apesar de ter exercido a profissão por pouco tempo - sete anos - ela fez muitos partos na aldeia. Conta que "pegou" nesse tempo, mais de 58 crianças em aldeias distintas entre os Tembé Tenetehar. E que só não "pegou" mais crianças porque as mulheres da aldeia começaram a ir para o hospital na cidade e foram, aos poucos, perdendo a confiança em seu conhecimento e em sua prática.

\section{A ATUAÇÃo COMO AGENTE DE SAÚdE NA ALDEIA}

Apesar de sua importância como parteira na comunidade e mesmo com o reconhecimento de seu trabalho pelos seus pares indígenas, sobretudo as mulheres em idade reprodutiva, Francisca nos últimos anos foi deixando de fazer os partos e praticar a pajelança. No que se refere ao ofício de partejar (que ela exerceu dos 33 aos 40 anos), há pelo menos 15 anos ela deixou de exercê-lo em face do impedimento imposto pelo Sistema Único de Saúde (SUS), ao qual foi incorporada como agente de saúde. Segundo ela, "[...] disseram que estava acontecendo muitos problemas e que não era mais pra mim me responsabilizar pelas mulheres grávidas, pois caso alguma coisa desse errado eu seria a culpada." (Francisca dos Santos Soares Tembé, 2015).

Nesse trecho da narrativa de Francisca fica evidenciado que na aldeia Tembé Ytuaçu, pelo menos no que se refere à realidade das parteiras indígenas, o respeito às lógicas culturais internas da comunidade, expressas em tais saberes tradicionais, não acontece como deveria.

\footnotetext{
${ }^{6}$ Que também pode ser uma mulher, como no caso de Francisca.

${ }^{7}$ Quando se trata de uma mulher, como dito na nota anterior.
} 
De fato, com a imposição do sistema de saúde indígena na aldeia, Francisca foi levada a abandonar suas práticas tradicionais do partejar, embora tenha sido incorporada ao mesmo sistema como agente de saúde. Em seu trabalho nesta nova função, ela foi recomendada a não fazer mais os partos sozinha - sem o acompanhamento de um médico - pois, se assim o fizesse, estaria pondo em risco a vida das gestantes e das crianças.

De acordo com Del Priore (2009), as mulheres benzedeiras, pajés e parteiras, possuem uma longa história na região amazônica. Desde o período colonial essas práticas eram exercidas por mulheres que tratavam, principalmente, de outras mulheres em um contexto em que praticamente não existiam médicos. Então as médicas eram elas que, por possuírem conhecimentos específicos e diferenciados daquele defendido pela ciência médica, com frequência, eram vistas e tratadas como suspeitas, acusadas de feitiçarias e sofriam perseguições tanto pelos inquisidores do Tribunal do Santo Ofício da Igreja Católica, instalado aqui no Brasil à época, como pelas autoridades civis que representavam o Estado brasileiro.

É importante lembrar que, durante o século XVIII, o Pará (que à época era Província do Grão Pará e Maranhão), foi palco de grandes embates entre agentes de cura que se empenharam em resolver o problema das epidemias de cólera e lepra que se alastravam, contexto em que as disputas de saberes (e poderes) entre a medicina científica e as práticas de cura tradicionais foram bastante evidentes em todo o Brasil. Santos et al. (2012, p. 12), ressaltam, por exemplo, que, durante muito tempo e até os dias atuais, a medicina científica conviveu com outras práticas de cura de caráter popular, sempre tentando impor seu saber como o único possível e com propriedade de explicar as causas e apontar a cura para as doenças. E assim, de acordo com os mesmos autores, "médicos, intelectuais e cientistas conviviam, muitas vezes de forma pouco harmoniosa com práticas populares dos pajés, benzedeiras, homeopatas, boticários, feiticeiros (sic), barbeiros, sangradores, espíritas, práticas estas consideradas como charlatanismo pelos médicos". Ao que parece (e a narrativa de Francisca confirma), esse embate entre o que Langdon e Wiik (2010) denominam de "sistemas de saúde" diferenciados culturalmente, permanece nos tempos atuais, contexto em que se observa a imposição do modelo biomédico sobre as práticas tradicionais de cura.

Como se sabe, foi na passagem do século XIX para o XX que a medicina social passou a desenvolver o projeto de medicalização da sociedade como parte de uma política mais ampla de higienização dos espaços sociais. Nestes termos e progressivamente, as parteiras foram sendo afastadas do cenário público. Isso em face da valorização da prática médica que acompanhou - e acompanha - o discurso higienista. A partir desse momento, elas vão sendo substituídas pelos médicos. Enfim, como se depreende de Barroso (2009), o parto se institucionaliza e o saber médico é legitimado em detrimento do saber da parteira que passa ser considerada uma prática ultrapassada e de risco às mulheres e suas crianças.

Particularmente entre os povos indígenas, a prática das parteiras vem sofrendo alterações a partir da instituição de políticas públicas voltadas para o projeto de atenção à saúde indígena, atualizado nas últimas décadas. Ferreira (2013), aponta que foi na década iniciada em 1970, que a Organização Mundial de Saúde (OMS) inseriu nas suas recomendações, tal proposição. E isso em "[...] consonância com a nova ordem internacional" (OMS, 1978, p. 3) e que o Estado Nacional integrasse as medicinas tradicionais a seus sistemas de saúde, inclusive os saberes e as práticas das parteiras.

Entretanto, somente em 2002, com a publicação do documento "Estratégias da OMS sobre a medicina tradicional, 2002-2005", a OMS passou a estimular os Estados Nacionais a regular, disciplinar e controlar as respectivas medicinas tradicionais (ORGANIZAÇÃO, 2002). Também, foram criadas diretrizes básicas para o estabelecimento das relações de cooperação entre a ciência médica - sistema oficial de saúde - e as medicinas tradicionais. Porém, esses processos todos têm sido difíceis de se efetivarem no âmbito da gestão pública. 
No Brasil, de acordo com Ferreira (2013, p. 205), as recomendações internacionais se efetivaram via políticas públicas “[...] delineadas como ações e programas governamentais voltados para a realização de objetivos específicos [...]", com o intuito de integrar as medicinas tradicionais ao sistema de saúde oficial. Dentre estas políticas, destaca-se a Política Nacional de Atenção à Saúde dos Povos Indígenas (PNASI), que considera as especificidades das medicinas indígenas, referindo-as como práticas tradicionais de saúde que operam a partir de lógicas culturais específicas no contexto de um sistema baseado nas relações cosmológicas, destacando que:

\begin{abstract}
As práticas de cura respondem a uma lógica interna de cada comunidade indígena e são produto de sua relação com o mundo espiritual e os seres do ambiente em que vivem. Essas práticas e concepções são, geralmente, recursos de saúde de eficácia empírica e simbólica, de acordo com a definição mais recente da OMS. (BRASIL, 2002, p. 16-17).
\end{abstract}

Observa-se que a $\mathrm{PNASI}^{8}$, apesar de considerar, em tese, que as práticas de cura tradicionais são detentoras de especificidades baseadas em lógicas internas, na prática esse reconhecimento nem sempre se apresenta. Desse modo e de acordo com seus relatos, para se tornar agente de saúde, há 18 anos, Francisca teve que se deslocar de sua aldeia até a capital do estado do Pará, Belém, para fazer um curso de capacitação promovido pela Fundação Nacional de Saúde (FUNASA). Nessa ocasião, ela foi orientada a não mais partejar nos domicílios, sob a justificativa de que haveria riscos à saúde das mulheres e das crianças nascidas pelas mãos da parteira. Ao mesmo tempo, na sua aldeia, as mulheres grávidas passaram a ser incentivadas pelo SUS - Sistema Único de Saúde - a realizarem o pré-natal com acompanhamento dos médicos e enfermeiros na cidade e a fazerem seus partos nos hospitais.

Francisca seguiu tais orientações, tendo deixado de fazer os partos há pelo menos 17 anos, lembrando que "[...] quando eles [o seu povo, sobretudo as mulheres em idade reprodutiva] começaram a conhecer a vida dos brancos nos hospitais, deixaram a confiança nas parteiras". No entanto, nesse espaço de tempo em que está trabalhando como agente de saúde, houve um caso de emergência que ela não pôde deixar de atender. Isso ocorreu há sete anos.

Ela relatou que nessa ocasião, uma mulher grávida da aldeia retornou, após ter sido assistida por médicos do hospital da cidade de Capitão Poço que haviam dito que não "estava na hora" da criança nascer. Então de volta à aldeia, a mulher deveria aguardar mais um pouco a hora do parto e no mesmo dia, à noite, sentiu as dores. No entanto, não houve tempo dela retornar ao hospital. Na ocasião, Francisca foi, então, chamada para atender a parturiente e o fez como os tantos atendimentos similares já feitos por ela anteriormente e todos bemsucedidos, com a ajuda dos encantados Caruanas.

É importante ressaltar que apesar das restrições sofridas em torno do seu ofício tradicional de partejar e de ter se tornado uma agente de saúde, Francisca ainda é chamada pelas mulheres grávidas na aldeia para "puxar a barriga" e "ajeitar o nenê na barriga". Isso acontece, segundo ela, porque as mulheres fazem o exame de ultrassonografia recomendado pelo médico, porém não confiam nos resultados e passam a procurá-la para ver a posição da criança no ventre. Assim, e embora tenha diminuído a frequência da procura pelos cuidados de Francisca, ela continua atendendo e cuidando da saúde das mulheres e das crianças da aldeia.

\footnotetext{
${ }^{8}$ A PNASI - Política Nacional de Atenção à Saúde dos Povos Indígenas - foi elaborada pela FUNASA Fundação Nacional de Saúde - e aprovada pelo Ministério da Saúde, por meio da Portaria 254, de 31 de janeiro de 2002 e publicada no Diário Oficial da União (DOU) número 26 - Seção 1, p.46 a 49, de 06 de fevereiro de 2002.
} 
A prática como benzedeira é a única, dentre as consideradas tradicionais, que ela continua a desenvolver com mais frequência. Assim, as pessoas da aldeia a procuram para rezar em crianças e adultos quando adoecem. A maior procura é para identificar as doenças, para, segundo ela, saber se é "quebranto", "bicho da água" ou "bicho do mato" ou "se é preciso ir ao médico", neste caso deixando nítido o reconhecimento dos limites de seus conhecimentos, recomendando que a pessoa procure o médico. Recorrentemente, ela é chamada a qualquer hora para rezar e benzer as pessoas acometidas pelos "males do corpo", momentos em que recomenda os banhos de ervas para tratar os casos identificados como doenças. Dentre os principais estão: o quebranto (que atinge mais as crianças), o parto quebrado (oriundo de "pouco resguardo" da mulher) e rasgaduras no corpo.

Ademais, as atividades desenvolvidas como agente de saúde não a satisfaz. Estas se restringem a acompanhar os casos identificados como doenças (de acordo com os preceitos da ciência médica), sob o cuidado principal de médicos e enfermeiros que atuam no Posto de Saúde da aldeia. Como já não parteja há alguns anos, ela considera que pode até esquecer como se faz. Fica aqui, portanto, o registro de uma situação preocupante que é o processo que inclusive é histórico -, de perda das suas crenças e costumes baseados em suas tradições culturais, o que inclui as práticas em torno da gestação das mulheres e o consequente nascimento das crianças.

\section{CONSIDERAÇÕES FINAIS}

A percepção das práticas e histórias das benzedeiras, pajés e parteiras como Francisca são reveladoras de uma tradição de medicina popular, cuja importância e eficácia nem sempre são valorizadas no contexto das políticas de atenção à saúde indígena que vem sendo implementadas pelo Estado, apontando para o risco de desenraizamento de valores culturais ancestrais, essenciais à preservação de suas tradições e de suas identidades. A história de vida de Francisca, particularmente sua experiência como parteira, pajé e benzedeira - e, mais recentemente, como agente de saúde - na Aldeia Tembé, aponta as alterações que o sistema de saúde impôs nos costumes relativos aos partos e nascimentos das crianças indígenas. Ao assumir a função de agente de saúde, Francisca ao tempo em que foi proibida de partejar, viuse também obrigada a aprender técnicas na área da saúde, que são próprias da ciência médica. Isso significa que, tal como há séculos ocorre, a medicina científica permanece impondo seu saber e seu domínio e assim, não reconhece a validade e a importância dos conhecimentos e práticas tradicionais de cura na comunidade.

No que diz respeito particularmente ao ofício de partejar, é nítida a insatisfação dela diante da proibição imposta pelo sistema médico de saúde, associada a uma preocupação por ela externada, de, sem poder exercitar seus saberes, vir a esquecer as técnicas e o conhecimento herdados de sua mãe e avó, temendo que, com o passar do tempo, tal saber se perca totalmente, já que não mais praticado na aldeia com a mesma frequência que fazia há alguns anos. Faz-se assim, urgente, pensarmos propostas de intervenção face às políticas de saúde das populações indígenas que de fato integrem os saberes tradicionais e diferenciados desses povos, pois se trata também de salvaguardar um patrimônio imaterial que significa muito para a história e para as suas identidades, particularmente para os Tembé Tenetherar.

\section{REFERÊNCIAS}

BARROSO, Iraci de Carvalho. Os saberes de parteiras tradicionais e o ofício de partejar em domicílio nas áreas rurais. PRACS - Revista Eletrônica de Humanidades do Curso de Ciências Sociais da UNIFAP, n. 2, p. 01-14, dez. 2009. 
BRASIL. Ministério da Saúde. Fundação Nacional de Saúde. Política Nacional de Atenção à Saúde dos Povos Indígenas. Brasília: Ministério da Saúde; Fundação Nacional de Saúde. 2002.

BOURDIEU, Pierre. A ilusão biográfica. In: AMADO, J. e FERREIRA, M. (Org.). Usos e abusos da história oral. 8a ed. Rio de Janeiro: Fundação Getúlio Vargas, 2006, p. 183-191.

DEL PRIORE, Mary. Ao sul do corpo: condição feminina, maternidades e mentalidades no Brasil Colônia. São Paulo: Editora UNESP, 2009.

FERREIRA, Luciane Ouriques. A emergência da medicina tradicional indígena no campo das políticas públicas. História, Ciência, Saúde - Manguinhos, Rio de Janeiro, v. 20, n. 1, p. 203-219, jan./mar. 2013.

LANGDON, Esther Jean.; WIIK, Flávio Braune. Antropologia, Saúde e Doença: uma introdução ao conceito de cultura aplicada às ciências da saúde. Revista Latino-Americana de Enfermagem, v. 18, n. 3, 2010.

LIMA, Zenaida. O Mundo Místico dos Caruanas e a Revolta de sua Ave. Belém: Cejup, 1992.

MAUÉS, Raimundo Heraldo. Medicinas populares e "pajelança cabocla" na Amazônia. In: ALVES, P. C.; MINAYO, M. C. de S. (Org.). Saúde e doença: um olhar antropológico. Rio de Janeiro: Editora FIOCRUZ, 1994. p. 73-81.

NEVES, Ivânia dos Santos. S. As histórias de Murué Suruí e Kudã’í Tembé: traduções e temporalidades. Revista Estudos de Literatura Brasileira Contemporânea. n. 53, Brasília, 2018.

ORGANIZAÇÃO MUNDIAL DE SAÚDE (OMS). Declaração de Alma-ata. Conferência Internacional sobre cuidados primários de saúde. Alma-ata, URSS: 6-12 de setembro, 1978.

ORGANIZAÇÃO MUNDIAL DE SAÚDE (OMS). Estratégias de la OMS sobre medicina tradicional 2002-2005. Genebra: Organização Mundial da Saúde. 2002.

PONTE, Vanderlúcia da Silva. Os Tenetehar-Tembé do Guamá e do Gurupi, Povo verdadeiro!: "saúde diferenciada", território e indianidade na ação pública local. 2014. Tese (Doutorado em Sociologia e Antropologia), Universidade Federal do Pará, 2014.

PONTE, Vanderlúcia da Silva; TEISSERENC, Maria José Aquino. "Para ser mulher verdadeira!" - os Tenetehara-Tembé: relações entre ritual, direitos e estratégias de afirmação cultural em ações locais. Nuevo Mundo-Mundos Nuevos, v. 01, p. 1-24, 2013. Disponível em: http://nuevomundo.revues.org/66051. Acesso em: 30 maio 2021.

SANTOS, Alessandra Carla Baia; SILVA, Andrei Ferreira; SAMPAIO, Danielle Leal; SENA, Lidiane Xavier; GOMES, Valquíria Rodrigues; LIMA, Vera Lúcia de Azevedo. Antropologia da saúde e da doença: contribuições para a construção de novas práticas em saúde. Revista NUFEN, v. 4, n. 2, 2012. 
SIMONIAN, Ligia Terezinha Lopes. Mulheres Pan-amazônidas: enciclopédia cooperativa de biografias (Org.). Belém: NAEA, 2011.

WAGLEY, Charles.; GALVÃO, Eduardo. Os índios Tenetehara: uma cultura em transição. Rio de Janeiro: Ministério da Educação e Cultura, 1961.

VAZ FILHO, Florêncio Almeida. Pajés, benzedores, puxadores e parteiras: os imprescindíveis sacerdotes do povo na Amazônia. Santarém: UFOPA, 2016. 